\title{
Novel Synthesis of benzyl-Methoxyl Protected Aspalathin Analog via C-Glucosylation of Pentamethoxy Dihydropropane
}

\author{
Pravin Kendrekar ${ }^{1 *}$, Mojalefa Setlai ${ }^{1}$, Sunil Tekale ${ }^{2}$, Rajita Ingle ${ }^{2}$, Chandrashekhar V. Kulkarni ${ }^{3}$, \\ Rajendra Pawar 2,* \\ 1 Unit for Drug Discovery Research (UDDR), Department of Health Sciences, Central University of Technology, Free State \\ (CUT), Private Bag X20539, Bloemfontein 9300, South Africa \\ 2 Department of Chemistry, Deogiri College, Aurangabad, 431005, Maharashtra, India \\ 3 Centre for Smart Materials School of Natural Sciences, University of Central Lancashire, Preston PR12HE United \\ Kingdom \\ * Correspondence: kkpravin@gmail.com (P.K.); rppawar@yahoo.com (R.P.);
}

Scopus Author ID 7003738785

Received: 8.11.2020; Revised: 3.01.2021; Accepted: 5.01.2021; Published: 17.01.2021

Abstract: The first report on a novel and efficient synthesis of benzyl-methoxy protected aspalathin derivative has been described via C-glucosylation of pentamethoxy dihydropropane. The synthesized compound was characterized by ${ }^{1} \mathrm{H},{ }^{13} \mathrm{C}$ NMR, COSY, and HSQC techniques.

Keywords: aspalathin;glucolysation;glycoside.

(C) 2020 by the authors. This article is an open-access article distributed under the terms and conditions of the Creative Commons Attribution (CC BY) license (https://creativecommons.org/licenses/by/4.0/).

\section{Introduction}

Glycoside is a molecule that contains a sugar moiety attached to another moiety through a glycosidic bond via its anomeric (C-1') carbon. The sugar moiety is known as glycone and another moiety as the glycone part of the glycoside. Glycosides can be linked via oxygen- (an $O$-glycoside), nitrogen- (a glycosylamine), sulfur- (a thioglycoside), or carbon- (a $C$-glycoside) glycosidic bond. Glycosides show important biological functions. As polymers, they are an important store of energy in plants that serve as food sources for animals and humans. Oligomeric glycosides on mammalian cell surfaces play an important role in the immune system. The glycone moiety usually renders the glycoside more water-soluble. Thus, glycosylation makes metabolite toxins and other unwanted secondary metabolites in mammals water-soluble for excretion by the kidneys. Many secondary metabolites in plants are glycosides. Some of these are toxins that protect the plant against herbivores. Plethoras of other activities in mammalian and human biology has been demonstrated [1-8]. Flavonoids normally accumulate in plants as $O$-glycosylated derivatives. However, several species, including major cereal crops, predominantly synthesize flavone $C$-glycosides. These are stable to hydrolysis and are biologically active both in plants and mammals. Activities ascribed to these plant secondary metabolites include them functioning as antioxidants [9-10], insect feeding attractants [11], antimicrobial agents [12], promoters of mycorrhizal symbioses [13], and UVprotective pigments [14]. 


\section{Materials and Methods}

Aspalathin (1a) (Figure 1) (3'- $\beta$-D-glucopyranosyl-2', 3, 4, 4', 6'pentahydroxydihydrochalcone) is a dihydrochalcone $C$-glucopyranoside. It was first characterized by Koeppen [15] and co-workers in 1965. Notably is the $\beta$-stereochemistry at the anomeric carbon. It occurs exclusively in leaves of Aspalathus linearis (rooibos) where it is the major component. It has recently received considerable interest due to its plasma sugar lowering properties [16-17]. Nothofagen (1b) (3'- $\beta$-D-glucopyranosyl-2', 4, 4', 6'tetrahydroxydihydrochalcone) differs from aspalathin in the absence of the 3-hydroxy on the A-ring. It occurs in a much lower concentration in rooibos.

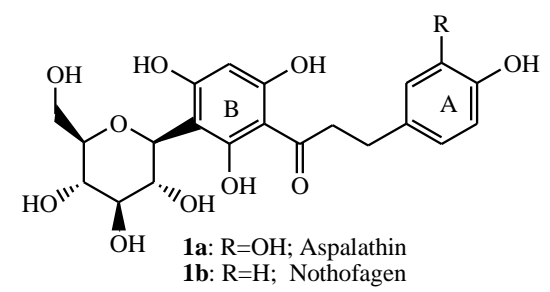

Figure 1. Structures of aspalathin (1a) and nothifagen (1b).<smiles>COc1cc(OC)cc(OC)c1</smiles>

(1)

(2) $\mathrm{R}=\mathrm{Me} 100 \%$

(3) $\mathrm{R}=\mathrm{Me}$<smiles>COc1cc(OC)c(C(=O)/C=C/c2ccc(OC)c(OC)c2)c(OC)c1</smiles>

(4) $\mathrm{R}=\mathrm{Me} 99 \%$<smiles>COc1cc(OC)c(CCCc2ccc(OC)c(OC)c2)c(OC)c1</smiles>

(5): $\mathrm{R}=\mathrm{Me} \quad 99 \%$
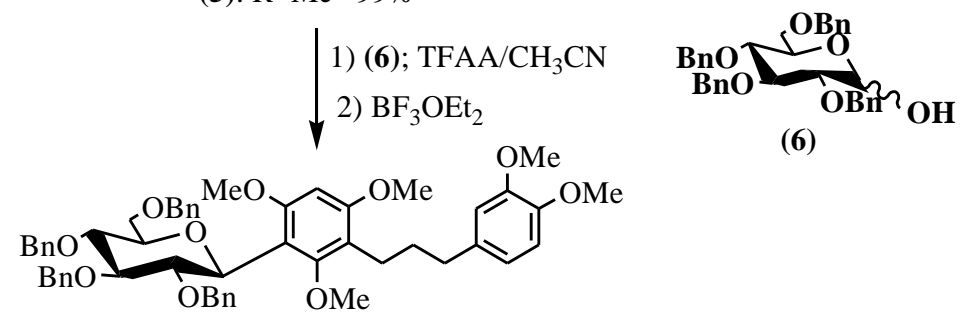

(6)

(7) $92 \%$

Scheme 1. Synthesis of diarylpropane (5) and $C$-diarylpropane-glycoside (7).

The isolation of naturally occurring $C$-aryl glycosides with important pharmacological properties [18-23] has prompted synthetic methods that are also relevant to the synthesis of 
aspalathin and analogs. The $C$-glycosidic bond confers stability to O-glycosides to both enzymatic and chemical hydrolysis and, thus, probably contributes to enhanced bioavailability. However, it is much more difficult to form a carbon-carbon bond than an ether bond, and $C$ glycoside synthesis has remained a challenge. The regio-and stereoselective requirements of the $C$-aryl linkage are the additional complications.

In continuation of our previous work on the synthesis of some bioactive heterocyclic compounds [24-27], in the present work, we report synthesis and characterization of benzylmethoxyl protected aspalathin analog via C-glucosylation of pentamethoxy dihydropropane (Scheme 1).

Table 1. High-pressure hydrogenation of fully OMe protected chalcone.

\begin{tabular}{c|c|c|c|c|c} 
Substrate & $\begin{array}{c}\text { Hydrogen } \\
\text { Pressure (Bar/PSi) }\end{array}$ & $\begin{array}{c}\mathbf{1 0 \%} \text { Pd/C } \\
(\text { Equivalent) }\end{array}$ & $\begin{array}{c}\text { Solvents } \\
\text { (EtOAc/MeOH (Ratio) }\end{array}$ & Time (h) & Yield (\%) \\
\hline 4 & $30 / 435$ & $(0.1)$ & $(50: 50)$ & 24 & $(100)$ \\
\hline 4 & R.T. Using $\mathrm{H}_{2}$, Balloon & $(0.2)$ & EtOAc/ $\mathrm{H}_{2} \mathrm{O} / \mathrm{Dil}, \mathrm{HCl}$ & Overnight & $99 \%$
\end{tabular}

Table 2. Synthesis of (7) via $C$-glycosylation of diarylpropane (5).

\begin{tabular}{|c|c|c|c|c|c|c|c|}
\hline Entry & $\begin{array}{l}\text { Sugar } \\
\text { donor }\end{array}$ & \multicolumn{2}{|c|}{ Catalyst (equivalents) } & Solvent & $\begin{array}{c}\text { Temperature } \\
\left({ }^{\circ} \mathrm{C}\right)\end{array}$ & $\begin{array}{c}\text { Time } \\
\text { (h) }\end{array}$ & $\begin{array}{c}\text { Yield } \\
(\%)\end{array}$ \\
\hline 1 & 6 & \multicolumn{2}{|c|}{$\mathrm{BF}_{3} \mathrm{OEt}_{2}(2)$} & DCM & 0 & 14 & 14 \\
\hline 2 & Sugar-1"\# & \multicolumn{2}{|c|}{ TMSOTf (2) } & DCM & -10 & 8 & 23 \\
\hline 3 & Sugar- $2^{\#}$ & \multicolumn{2}{|c|}{$\mathrm{BF}_{3} \mathrm{OEt}_{2}(2)$} & DCM & -20 & 6 & 42 \\
\hline 4 & Sugar- $3^{\#}$ & \multicolumn{2}{|c|}{$\mathrm{SnCl}_{4}(2)$} & DCM & 0 & 7 & 30 \\
\hline 5 & 6 & TFAA* (3) & $\mathrm{BF}_{3} \mathrm{OEt}_{2}(2)$ & DCM & -12 & 6 & 59 \\
\hline 6 & 6 & TFAA* $^{*}(3)$ & $\mathrm{BF}_{3} \mathrm{OEt}_{2}(2)$ & $\mathrm{CH}_{3} \mathrm{CN}$ & -12 & 3 & 92 \\
\hline
\end{tabular}

* Preactivation with TFAA was essential for the coupling reaction to take place.

\#Sugar-1: 2, 3, 4, 6-tetra-O-benzylglucosyl acetate, Sugar-2: 2, 3, 4, 6-tetra-O-benzylglucosyl acetamide, Sugar3: 2, 3, 4, 6-tetra-O-benzyl-glycopyranosyl fluoride.

C-aryl glycosylation has been reviewed by Palmacci [28] and Seeberger [29]. The substituents may influence glycosidic bond formation's regioselectivity on the aromatic ring and the reaction conditions such as the temperature and pressure employed. C-aryl glycosidic bond formation's stereoselectivity was influenced by the structure of carbohydrate moiety, e.g., neighboring group effects, anomeric effects, and synthetic conditions such as the choice of catalysts and solvents.

\section{Results and Discussion}

The methoxy-protected chalcone (4) was obtained in quantitative yields. High-pressure catalytic hydrogenative reduction of (4) gave the corresponding 1, 3-diarylpropane (5) quantitatively (Scheme 1) (Table 1). Salient in the NMR of (5) is the following: The absence of the two chalcone proton resonances in the ${ }^{1} \mathrm{H}$ NMR spectrum $\left[\mathrm{H}_{\alpha}(\mathrm{d}, 7.25 \mathrm{ppm}, \mathrm{J}=15.5 \mathrm{~Hz})\right.$ and $\mathrm{H}_{\beta}(\mathrm{d}, 6.88 \mathrm{ppm}, \mathrm{J}=15.5 \mathrm{~Hz})$ for corresponding chalcone, and the absence of the carbonyl resonance $(\delta=196)$ in the ${ }^{13} \mathrm{C}$ NMR; The three propane $\mathrm{CH}_{2}$ groups are represented in the ${ }^{1} \mathrm{H}$ $\mathrm{NMR}$ at $2.58 \mathrm{ppm}$ (two overlapping benzylic $\mathrm{CH}_{2}$ groups that integrate four hydrogen atoms) and $1.77 \mathrm{ppm}$ (a multiplet that integrates two hydrogen atoms). They correspond to two crosspeaks at 35.5 and $31.1 \mathrm{ppm}$ in the HSQC; The 1,3-diarylpropane- $C$-glycoside (7) was subsequently obtained in almost quantitative isolated yield (92\%, Entry 6, Table 2) from (6) via the trifluoroacetic anhydride (TFAA) method described under approach 1 (preactivation of the anomeric $\mathrm{OH}$ with TFAA) (Scheme 1); The glycosyl fluoride and $\mathrm{BF}_{3} \mathrm{OEt}_{2}$ gave (7) in a yield of only $42 \%$ (Entry 3 , Table 2 ). The $C$-diarylpropane-glycoside (7) was characterized by the following observations: 
a) It has complex ${ }^{1} \mathrm{H}$ and ${ }^{13} \mathrm{C}$ NMR spectra at room temperature due to the expected rotational isomerism about the glycosidic carbon-carbon bond. Heating of the sample to $140^{\circ} \mathrm{C}$ in DMSO-d6 was required for NMR elucidation.

b) The anomeric proton resonates at $4.73 \mathrm{ppm}$ in the ${ }^{1} \mathrm{H}$ and its corresponding $\mathrm{C}$ at $74.2 \mathrm{ppm}$ in the ${ }^{13} \mathrm{C}$ NMR spectra. These correspond with a carbon-carbon and not carbon-oxygen bond.

The $\mathrm{J}=9.8 \mathrm{~Hz}$ coupling constant agrees with the required $\beta$-stereochemistry on the anomeric carbon.

An edited two-dimensional HSQC experiment; $\left(\mathrm{CH}\right.$ and $\mathrm{CH}_{3}$ cross-peaks having a different color from $\mathrm{CH}_{2}$ cross-peaks) allows facile differentiation between the benzylic protons $\left(\mathrm{CH}_{2}\right)$ of the benzyl protection groups and the anomeric sugar proton $(\mathrm{CH})$, all of which resonate in the range of $\delta 4.00-5.20 \mathrm{ppm}$.

We thus proved our hypothesis that the carbonyl group in chalcone or the phloroacetophenone moiety prevents $C$-glycosylation. Initial efforts to regenerate the carbonyl group via oxidation of (7) with Dess-Martin reagent, IBX (o-iodoxybenzoic acid), CAN (ceric ammonium nitrate), pyridine-dichromate, $\mathrm{Na}_{2} \mathrm{Cr}_{2} \mathrm{O}_{7}$, and DDQ (dichlorodicyanoquinone) under anhydrous conditions failed. Upon further literature search and model reactions (Table 3 ) with the diarylpropane (5), we realized that the presence of water as a source of oxygen is essential for this oxidation. Upon treatment of (5) with DDQ in the presence of $\mathrm{H}_{2} \mathrm{O}(1.5$ equivalent), the corresponding dihydrochalcone (4) was obtained quantitatively at room temperature (Scheme 2). Compared to other oxidative conditions, it is mild with water as the oxygen source.

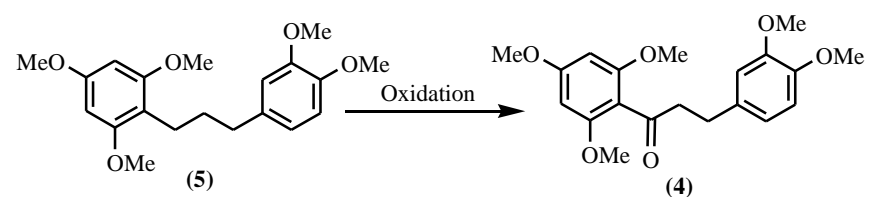

Scheme 2. Benzylic oxidation of the diarylpropane (5).

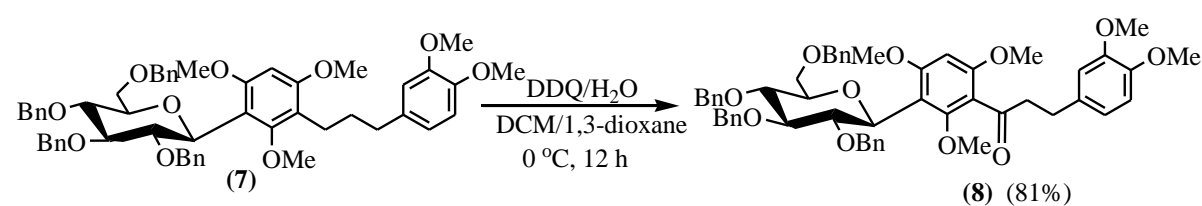

Scheme 3. Optimized synthesis of methyl-benzyl-protected aspalathin (8) via benzylic oxidation of (7).

Table 3. Oxidation condition for the synthesis of (5) at room temperature.

\begin{tabular}{l|c|c|c|c} 
Entry & Oxidant & Solvents (2:1) & Time (h) & Yield (\%) \\
\hline 1 & IBX & Acetone* & 14 & 0 \\
\hline 2 & Des-Martin & DCM $^{*}$ & 8 & 0 \\
\hline 3 & $\mathrm{CAN}$ & $\mathrm{DCM}^{*}$ & 6 & 0 \\
\hline 4 & $\mathrm{DCM}^{*}$ & 7 & 0 \\
\hline 5 & Pyridine-dichromate & $\mathrm{DCM}^{*}$ & 6 & 0 \\
\hline 6 & $\mathrm{Na}_{2} \mathrm{Cr}_{2} \mathrm{O}_{7}$ & $\mathrm{DCM}^{*}$ Dioxane $^{*}$ & 3 & 0 \\
\hline 7 & $\mathrm{DDQ}$ & $\mathrm{DCM}^{\#}$ & 14 & 14 \\
\hline 8 & $\mathrm{IBX}$ & $\mathrm{DCM}^{\#}$ & 8 & 23 \\
\hline 9 & Des-Martin & $\mathrm{DCM}^{\#}$ & 6 & 33 \\
\hline 10 & $\mathrm{CAN}$ & $\mathrm{DCM}^{\#}$ & 7 & 30 \\
\hline 11 & pyridine-dichromate & $\mathrm{DCM}^{\#}$ & 6 & 59 \\
\hline 12 & $\mathrm{Na}_{2} \mathrm{Cr} \mathrm{O}_{7}$ & $\mathrm{DCM}^{*} / \mathrm{Dioxane}^{\#}$ & 3 & 92
\end{tabular}

* Anhydrous solvents were used in reactions

\# 1.5 equivalent of $\mathrm{H}_{2} \mathrm{O}$ was present in the reaction solvents 
Table 4. Optimized oxidation conditions for the synthesis of $C$-dihydrochalcone glycoside (7).

\begin{tabular}{c|c|c|c|c|c} 
Entry & Oxidant (Eq) & Solvents $(\mathbf{2 : 1 )}$ & Temp. $\left({ }^{\mathbf{o}} \mathbf{C}\right)$ & Time (h) & Yield \% \\
\hline 1 & DDQ (4) & DCM/Dioxane & r.t. & 2 & 44 \\
\hline 2 & DDQ (4) & DCM/Dioxane & 0 & 12 & 81
\end{tabular}

\# $\quad 1.5$ equivalent of $\mathrm{H}_{2} \mathrm{O}$ was present in the reaction solvents

The same treatment of (7) with DDQ at room temperature under the conditions optimized for (5) yielded the expected dihydrochalcone- $C$-glycoside (8) in a $44 \%$ yield. Upon lowering the reaction temperature to $0{ }^{\circ} \mathrm{C}$, the reaction proceeded slower but produced a higher yield $(81 \%)$ (Scheme 3, Table 4). We attributed this to the partial removal of the aliphatic benzyl protection groups on the sugar moiety with DDQ at room temperature. The NMR of (8) also required elevated temperature $\left(140{ }^{\circ} \mathrm{C}\right)$ to remove rotational isomerism and simplify interpretation. Notable are the following: The carbonyl resonance at $\delta 198.4$ in the ${ }^{13} \mathrm{C}$ NMR spectrum; Two multiplets at $\delta 3.05$ and 2.93 in the ${ }^{1} \mathrm{H}$ NMR. These $\mathrm{CH}_{2}$ resonances correlate with the carbon resonances at $\delta 38.8$ and $19.7 \mathrm{ppm}$, respectively, in an edited HSQC experiment. The two multiplets also cross-couple to each other in the COSY spectrum. They represent the dihydrochalcone's $\mathrm{CH} 2-\mathrm{CH} 2$ moiety; the anomeric proton of the sugar moiety resonates as a doublet at $\delta 4.73 \mathrm{ppm}$ that correlates with the anomeric carbon at $\delta 73.6 \mathrm{ppm}$ in the edited HSQC. The $\mathrm{J}=9.8 \mathrm{~Hz}$ coupling constant indicates $\beta$-stereochemistry for the $C$ glycosidic bond; The four benzylic $\mathrm{CH}_{2}$ resonances in the $\delta 4.55$ to $4.90 \mathrm{ppm}$ range of the ${ }^{1} \mathrm{H}$ NMR spectrum indicate that the four benzyl groups on the sugar moiety remained intact (stable to the oxidation conditions); The same treatment of (7) with DDQ at room temperature under the conditions optimized for (5) yielded the expected dihydrochalcone- $C$-glycoside (8) in a $44 \%$ yield. Upon lowering the reaction temperature to $0{ }^{\circ} \mathrm{C}$, the reaction proceeded slower but produced a higher yield (81\%) (Scheme 3, Table 4). We attributed this to the partial removal of the aliphatic benzyl protection groups on the sugar moiety with DDQ at room temperature.

\section{Conclusions}

Thus the present protocol represents the first synthesis of methyl-benzyl-protected aspalathin analog (8). However, attempts to deprotect the analog (8) using $\mathrm{BBr}_{3}$ could not lead to the successful synthesis of aspalathin. Efforts for demethylation by using the excess of $\mathrm{BBr}_{3}$ lead to a breakdown of sugar moieties and decomposition.

\section{Funding}

This research received no external funding.

\section{Acknowledgments}

This research has no acknowledgment.

\section{Conflicts of Interest}

The authors declare no conflict of interest.

\section{References}

1. Isono, K. Nucleoside antibiotics: Structure, biologicalactivity, and biosynthesis. The Journal of Antibiotics 1988, 41, 1711-1739, https://doi.org/10.7164/antibiotics.41.1711.

2. Cirak, C.; Radusiene, J. Factors affecting the variation of bioactive compounds in Hypericumspecies. Biologia Futura 2019, 70, 198-209, https://doi.org/10.1556/019.70.2019.25. 
3. Wang, M.; Li, J.; Rangarajan, M.; Shao,Y.; LaVoie, E.J.; Huang,T.-C.; Ho, C.-T. Antioxidative phenolic compounds froms age (Salviaofficinalis). J. Agric. Food Chem. 1998, 46, 4869-4873, https://doi.org/10.1021/jf980614b.

4. Ayan, A.K.; Radušienè, J.; Çirak, C.; Janulis, V. Secondary metabolites of Hypericum scabrum and Hypericum bupleuroides. Pharmaceutical Biology 2009, 4, 847-853, https://doi.org/10.1080/13880200902942436.

5. Jain, R.; Beyer, H.G.; Standish, R. Proceedings of the National Academy of Sciences, India, Section A:Physical Sciences. Volume 77, 2007; pp. 99-100.

6. Jung, H.-A.; Su, B-N.; Keller, W.J.; Mehta, R.G.; Kinghorn, A.D. Antioxidant xanthones from the pericarp of Garciniam angostana (Mangosteen). Journal of Agriculture and Food Chemistry 2006, 54, 2077-2082, https://doi.org/10.1021/jf052649z.

7. Subramoniam, A. Plants with anti-diabetes mellitus properties. Boca Raton: CRC Press, 2016; https://doi.org/10.1201/9781315371481.

8. Giri, P.; Singh, I. Development and evaluation of muco adhesive tablets of cinnarizine using carboxymethylated guargum by compression coating technique. Biointerface Researchin Applied Chemistry 2020, 10, 6076-6081, https://doi.org/10.33263/BRIAC105.63656376.

9. Fouda, A.E.-A.S.; El-Maksoud, S.A.A.; El-Habab, A.T.; Ibrahim, A.R. Synthesis and characterization of newethoxylated carbohydrate based surfactants for corrosion inhibition of low cost steel in aqueous solutions. Biointerface Research in Applied Chemistry 2021, 11, 9382-9404, https://doi.org/10.33263/BRIAC112.93829404.

10. Ramarathnam, N.; Osawa, T.; Namiki, M.; Kawakishi, S. Chemical studies on novel rice hull antioxidants. 2. Identification of isovitexin, a C-glycosyl flavonoid. J. Agri. Food. Chem. 1989, 37, 316-319, https://doi.org/10.1021/jf00086a009.

11. Xiao, J.; Capanoglu, E.; Jassbi, A.R.; Miron, A. Dietary phytochemicals: Nutrition and health advance on the flavonoid C-glycosides and health benefits. Dietary Phytochemicals: Nutrition and Health 2015, s29s45, https://doi.org/10.1080/10408398.2015.1067595.

12. Dinda, B.; Bhattacharya, A.; Takayanagi, H.; Harigaya,Y. Antimicrobial C-Glucoside from aerial parts of Diospyros nigra. Chem. Pharm. Bull. 2006, 54, 679-681, https://doi.org/10.1248/cpb.54.679.

13. Akiyama, K.; Matsuoka, H.; Hayashi, H. Isolation and identification of a phosphate deficiency-induced Cglycosyl flavonoid that stimulates Arbuscular Mycorrhiza formation in melon roots. Molecular PlantMicrobe Interactions® 2002, 15, 334-340, https://doi.org/10.1094/MPMI.2002.15.4.334.

14. Middleton, E.M.; Teramura, A.H. The role of flavonol glycosides and carotenoids in protecting soybean from ultraviolet-B damage. Plant Physiology 1993, 103,741-752, https://doi.org/10.1104/pp.103.3.741.

15. Pérez Gutierrez, R. M.; García Campoy, A.H.; Paredes Carrera, S.P.; Muñiz Ramirez, A.; Mota Flores, J.M.; Flores Valle, S.O. 3'-O- $\beta$-d-glucopyranosyl- $\alpha, 4,2^{\prime}, 4^{\prime}, 6^{\prime}$-pentahydroxy-dihydrochalcone, from Bark of Eysenhardtia polystachya Prevents Diabetic Nephropathy via Inhibiting Protein Glycation in STZNicotinamide Induced Diabetic Mice. Molecules 2019, 24, https://doi.org/10.3390/molecules24071214.

16. Kawano, A.; Nakamura, H.; Hata, S.-I.; Minakawa, M.; Miura, Y.; Yagasaki, K. Hypoglycemic effect of aspalathin, a rooibos tea component from Aspalathus linearis, in type 2 diabetic model $\mathrm{db} / \mathrm{db}$ mice. Phytomedicine : International Journal of Phytotherapy And Phytopharmacology 2009, 16, 437-443, https://doi.org/10.1016/j.phymed.2008.11.009.

17. Plante, O.J.; Palmacci, E.R.; Andrade, R.B.; Seeberger, P.H. Oligosaccharide synthesis with glycosyl phosphate and dithiophosphate triesters as glycosylating agents. Journal of the American Chemical Society 2001, 123, 9545-9554, https://doi.org/10.1021/ja016227r.

18. Kitamura, K.; Ando, Y.; Matsumoto, T.; Suzuki, K. Total synthesis of aryl $C$-glycoside natural products: Strategies and tactics Chemical Reviews 2018, 118, 1495-1598, https://doi.org/10.1021/acs.chemrev.7b00380

19. Ben, A.; Yamauchi, T.; Matsumoto, T.; Suzuki, K. Sc(OTf) $)_{3}$ as efficient catalyst for aryl C-glycoside synthesis. Chem Inform 2004, 35, 225-230, https://doi.org/10.1002/chin.200423210.

20. Li, Y.; Mo, H.; Lian, G.; Yu, B. Revisit of the phenol O-glycosylation with glycosyl imidates, $\mathrm{BF}_{3} \cdot \mathrm{OEt}_{2}$ is a better catalyst than TMSOTf. Carbohydrate Research 2012, 363, 14-22, https://doi.org/10.1016/j.carres.2012.09.025.

21. Yamauchi, T.; Watanabe, Y.; Suzuki, K.; Matsumoto, T. Facile One-pot synthesis of resorcinol bis-Cglycosides possessing two identical- sugar moieties. Synthesis 2006, 2006, 2818-2824, https://doi.org/10.1055/s-2006-942526.

22. Alexei, V. Handbook of Chemical Glycosylation: Advances in Stereoselectivity and Therapeutic Relevance. 2008, Wiley-VCH.

23. Kaliappan, K.P.; Subrahmanyam, A.V. A New versatile strategy for C-aryl glycosides. Organic Letters 2007, 9, 1121-1124, https://doi.org/10.1021/ol0701159.

24. Gore,V.A.; Tekale, S.U.; Bhale, S.P.; Rajani, D.P.; Domb, A.J.; Pawar, R.P. Synthesis and biological evaluation of novel thiazole hydrazines as antimicrobial and antimalarial agents. Letters in Applied NanoBioScience 2021, 10, 1846-1855, https://doi.org/10.33263/LIANBS101.18461855. 
25. Kaminwar, N.S.; Tekale, S.U.; Chidrawar, A.B.; Kótai, L.; Pawar, R.P. Eco-friendly synthesis of 1,4dihydropyrano-[2,3-c]pyrazoles using copper nanoparticles grafted on carbon microsphere as a heterogeneous catalyst. Letters in Applied NanoBioScience 2020, 9, 1521-1528, https://doi.org/10.33263/LIANBS94.15211528.

26. Bhale, S.; Gore, V.; Tekale, S.; Pawar, R. Synthesis, characterization and antimicrobial activity of Ni(II), $\mathrm{Zn}(\mathrm{II})$, and Cd(II) complexes of 3/4-bromobenzoic acid (phenyl-pyridine-2-yl-methylene)-hydrazide ligand. Letters in Applied NanoBioScience 2020, 9, 1529-1537, https://doi.org/10.33263/LIANBS94.15291537.

27. Kendrekar, P.; Mashele, S.; Tekale, S.; Pawar, R. Synthesis of some novel and potent anti-plasmodial aminoalkyl chalcone derivatives. Biointerface Research in Applied Chemistry 2020, 10, 6076-6081, https://doi.org/10.33263/BRIAC105.60766081.

28. Palmacci, E.R.; Seeberger, P.H. Synthesis of C-aryl and C-alkyl glycosides using glycosyl phosphates. Organic Letters 2001, 3, 1547-1550, https://doi.org/10.1021/ol0158462.

29. Nakajima, N.; Abe, R.; Yonemitsu, O. 3-Methoxybenzyl(3-MPM) and 3,5-dimethoxybenzyl(3,5-DMPM) protecting groups for the hydroxy functionless readily removable than 4-methoxybenzyl(MPM) and 3,4dimethoxybenzyl (DMPM) protecting groups by DDQ oxidation. Chemical and Pharmaceutical Bulletein 1988, 36, 4244-4247, https://doi.org/10.1248/cpb.36.4244. 